09

\title{
Формирование тонкого люминесцирующего слоя в кристаллах LiF под действием излучения тлеющего разряда
}

\author{
(C) А.А. Тютрин ${ }^{1}$, Д.С. Глазунов ${ }^{1}$, А.Л. Ракевич ${ }^{1}$, \\ Е.Ф. Мартынович ${ }^{1,2,9}$ \\ ${ }^{1}$ Иркутский фрилиал Института лазерной фризики СО РАН, Иркутск, \\ Россия \\ ${ }^{2}$ Иркутский государственный университет, Иркутск, Россия \\ ๑ E-mail: filial@ilph.irk.ru
}

Поступило в Редакцию 6 декабря 2017 г.

Средствами конфокальной сканирующей люминесцентной микроскопии с временны́м разрешением методом времякоррелированного счета одиночных фотонов исследовано образование тонких слоев люминесцирующих дефектов на гранях плоских образцов кристаллов фторида лития, размещенных в положительном столбе и темном фарадеевом пространстве тлеющего газового разряда. По характеристикам спектров и кинетики люминесценции, возникшей после облучения, установлено, что в поверхностных слоях кристаллов образуются агрегатные центры окраски. Рассмотрена роль электронов, ионов и фотонов газового разряда в механизме дефектообразования. Показано, что дефекты образуются под действием фотонов вакуумного ультрафиолета. Методом термостимулированной люминесценции измерено распределение интенсивности вакуумного ультрафиолетового излучения в разрядном промежутке. Основным источником этого излучения являются области анодного и катодного падения напряжения в тлеющем разряде.

DOI: 10.21883/PJTF.2018.15.46435.17145

В последние годы существенно возрос интерес к радиационно-оптическим технологиям, в которых центры окраски (ЦО), образованные как в объеме, так и в поверхностных слоях диэлектрических материалов, используются в качестве рабочих квантовых систем. Например, авторами [1] разработаны методы и средства скрытой маркировки товаров, документов, художественных произведений с помощью кодированных 
люминесцентных меток на основе ЦО в частицах LiF на специальном пленочном носителе. В работе [2] разработан твердотельный детектор рентгеновского излучения на тонких пленках LiF на основе считывания фотолюминесценции ЦО. В [3] реализована технология записи микротекста в тонком слое монокристалла при использовании вакуумного ультрафиолета (ВУФ) от лазерно-индуцированной плазмы, сфокусированного с помощью объектива Шварцшильда. В [4] исследован механизм образования ЦО в тонком приповерхностном слое кристалла $\mathrm{LiF}$ под действием ВУФ-излучения барьерного разряда в воздухе атмосферного давления. Разрабатываются высокоэффективные люминесцентные методы исследования высоконелинейного взаимодействия света и вещества [5]. Таким образом, изучение ЦО, механизмов их образования при различных физических воздействиях и развитие различных приложений, связанных с ними, остаются актуальной задачей.

В настоящей работе исследуются возможности создания ЦО в приповерхностных слоях монокристаллов LiF, размещенных в положительном столбе и темном фарадеевом пространстве тлеющего разряда в воздухе пониженного давления. Применение такого разряда для образования тонких люминесцирующих слоев на кристаллах и пленках практически не изучалось. Это было обусловлено сложностью регистрации малых количеств ЦО, поскольку последние в таких условиях могут создаваться лишь в тонких слоях исследуемых образцов. Регистрация таких центров и изучение их характеристик требуют использования современных высокочувствительных методов исследования.

Цель работы заключалась в определении типов формирующихся ЦО, изучении спектрально-кинетических характеристик их люминесценции, раскрытии механизма их образования и выявлении характерных зон тлеющего разряда, в которых дефектообразование наиболее эффективно.

Экспериментальная установка состоит из вакуумной камеры, внутри которой размещена стеклянная трубка радиусом $2 \mathrm{~cm}$, с обоих концов которой установлены электроды на расстоянии $6 \mathrm{~cm}$. В камере формировался тлеющий разряд в воздухе при давлении 1-10 Torr. Тлеющий разряд при таком давлении характеризуется наличием основных протяженных участков: положительного столба и темного фарадеева пространства. Кристаллы $\mathrm{LiF}$ размещались в этих областях.

Облученные образцы исследовались с помощью конфокального сканирующего люминесцентного микроскопа с временны́м разрешением

Письма в ЖТФ, 2018, том 44, вып. 15 
MicroTime 200 (PicoQuant GmbH), оснащенного спектрометром Ocean Optics QE65000. Для расчета глубины проникновения электронов разряда в кристалл проводилось моделирование их траекторий в кристалл с помощью программного пакета CASINO V2 [6]. Распределение интенсивности ВУФ-излучения вдоль разряда измерялось термолюминесцентным методом с помощью термолюминофора $\mathrm{CaSO}_{4} \cdot \mathrm{Mn}$, чувствительного к излучению в спектральной области короче $130 \mathrm{~nm}$ [7]. Для этого медная пластинка, покрытая слоем термолюминофора, размещалась в миниатюрной диафрагмированной ячейке. Ячейка устанавливалась на внутренней стенке разрядной трубки на разных расстояниях между электродами. Конструкция ячейки позволяла регистрировать излучение, испускаемое преимущественно в направлении, перпендикулярном направлению разряда. Термолюминофор при воздействии ВУФ-излучения запасал его энергию, которая затем высвобождалась при нагревании в пике термовысвечивания при $100^{\circ} \mathrm{C}$ в спектральной полосе с максимумом $\sim 500 \mathrm{~nm}[8]$. Распределение интенсивности регистрируемых термопиков отражает распределение интенсивности ВУФ-излучения вдоль разряда.

На рис. 1, $a$ приведены четыре спектра (по одному спектру для каждой из сторон образца) двух кристаллов LiF, облученных в положительном столбе и темном фарадеевом пространстве тлеющего разряда при постоянном напряжении $1.6 \mathrm{kV}$ и токе $1.2 \mathrm{~mA}$, а на рис. $1, b$ представлена кинетика люминесценции. Результаты измерений люминесценции показывают, что в кристаллах $\mathrm{LiF}$ образовались два основных типа агрегатных ЦО, а именно $F_{3}^{+}$- и $F_{2}$-центры, которые имеют максимумы полос свечения 540 и $680 \mathrm{~nm}$ и постоянные времени затухания 6.8 и $17.8 \mathrm{~ns}$. В пределах погрешности эксперимента $(\sim 10 \%)$ эти значения совпадают с известными значениями для данных ЦО в объеме образцов [9]. Постоянные времени затухания для других сторон имеют аналогичные значения.

Основным механизмом дефектообразования в щелочно-галоидных кристаллах является распад анионных экситонов на френкелевские пары [10], сопровождающийся последующими процессами перезарядки, миграции и агрегации с образованием стабильных люминесцирующих агрегатных ЦО [9]. Поэтому для дефектообразования необходима межзонная ионизация. Потенциально ее могут обеспечить три компонента тлеющего разряда: электроны, ионы и фотоны с энергией больше ширины запрещенной зоны, которая для $\mathrm{LiF}$ по разным данным составляет 13.6 или $14.2 \mathrm{eV}[9]$. 

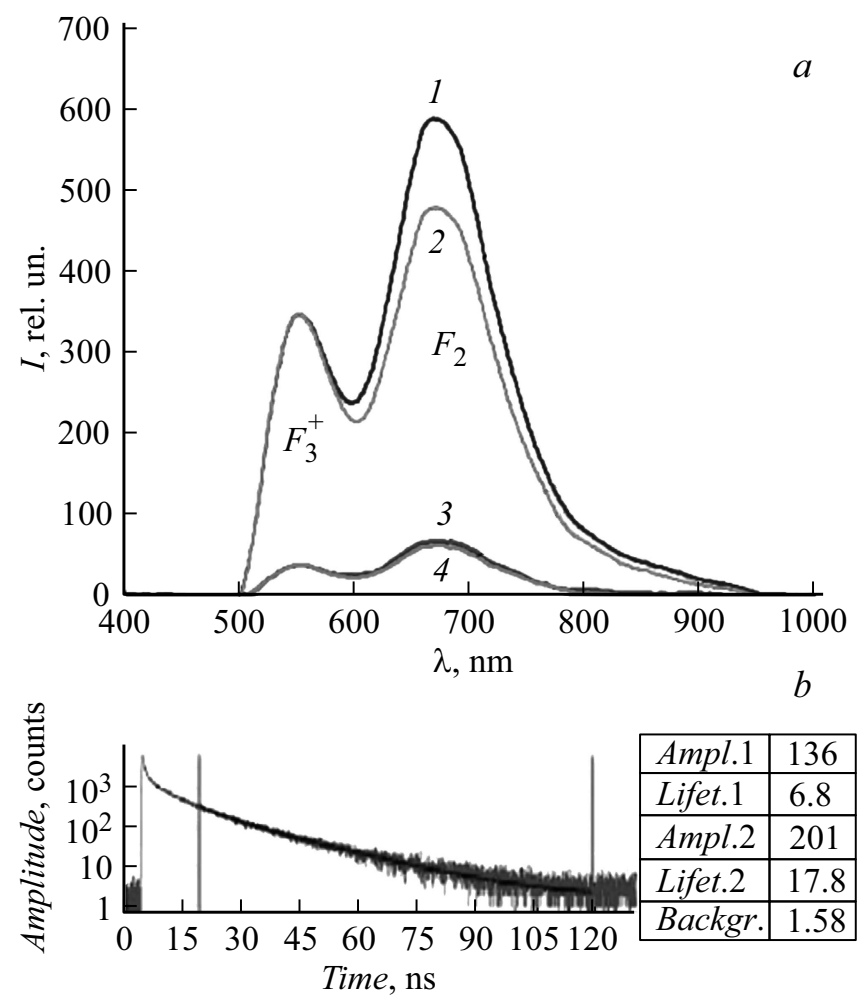

Рис. 1. Спектры $(a)$ и кинетика $(b)$ люминесценции облученных кристаллов. Возбуждение пикосекундными лазерными импульсами с длиной волны $470 \mathrm{~nm}$, светофильтр с пропусканием от $500 \mathrm{~nm}: 1$ и 3 - для образца в положительном столбе, 2 и 4 - в темном фарадеевом пространстве, 1 и 4 - для анодной стороны (обращенной к аноду), 2 и 3 - для катодной стороны. Внизу справа приведены результаты программного разложения кинетической кривой на два временны́х компонента (1 и 2); символ Lifet. означает величину времени затухания (в ns), а Ampl. - амплитуду (в относительных единицах) для этих компонентов; Backgr. - фон.

Рассмотрим полученный результат с позиции действия на кристалл электронов разряда. Учитывая направление движения электронов к аноду, следует ожидать, что катодные стороны кристаллов должны

Письма в ЖТФ, 2018, том 44, вып. 15 


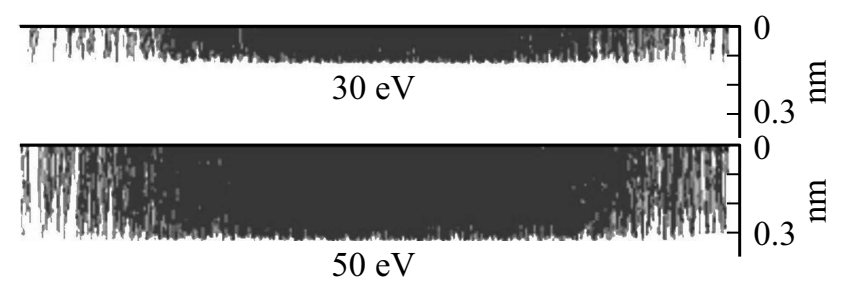

Рис. 2. Результаты моделирования проникновения пучка электронов с энергиями 30 и $50 \mathrm{eV}$ в монокристалл $\mathrm{LiF}$.

иметь более высокие интенсивности фотолюминесценции, чем анодные стороны. Для образца, облученного в фарадеевом пространстве (кривые 2 и 4 на рис. 1), казалось бы, данное ожидание реализуется. Однако соответствующие результаты для образца, облученного в положительном столбе (кривые 1 и 3), противоречат этому ожиданию. Фактически это первый аргумент против электронного механизма.

В областях темного фарадеева пространства и положительного столба энергия электронов заметно меньше, чем в приэлектродных областях разряда. Это связано с неравномерным распределением напряженности электрического поля в тлеющем разряде. Границей энергий для электронов в этих областях могут служить значения в диапазоне 30-40 eV [11], которые соответствуют высокоэнергетическому „хвосту“ функции распределения электронов по энергии. Электроны с такими энергиями в этих областях могли бы создавать радиационные дефекты в кристалле LiF. Однако подобные электроны проникают в кристалл лишь на малую глубину. Расчеты, результаты которых представлены на рис. 2, показывают, что глубина проникновения электронов в кристалл не превышает $\sim 0.3 \mathrm{~nm}$, что сравнимо с постоянной решетки (4.0279 $\AA$ ).

Агрегатные ЦО, образованные под действием этих электронов, являются поверхностными и должны отличаться по оптическим характеристикам от центров, находящихся в объеме. Например, по данным [12] поверхностные $F_{2}$-центры имеют спектральную полосу поглощения с максимумом $635 \mathrm{~nm}$ (вместо $440 \mathrm{~nm}$ ) и полосу люминесценции с максимумом $770 \mathrm{~nm}$ (вместо $680 \mathrm{~nm}$ для объемных $F_{2}$-центров). В описанных выше условиях облучения ЦО с характеристиками, присущими объемным центрам, под действием электронов вообще не должны появляться. Однако в наших экспериментах регистрируются именно они. Это второй

Письма в ЖТФ, 2018, том 44, вып. 15 


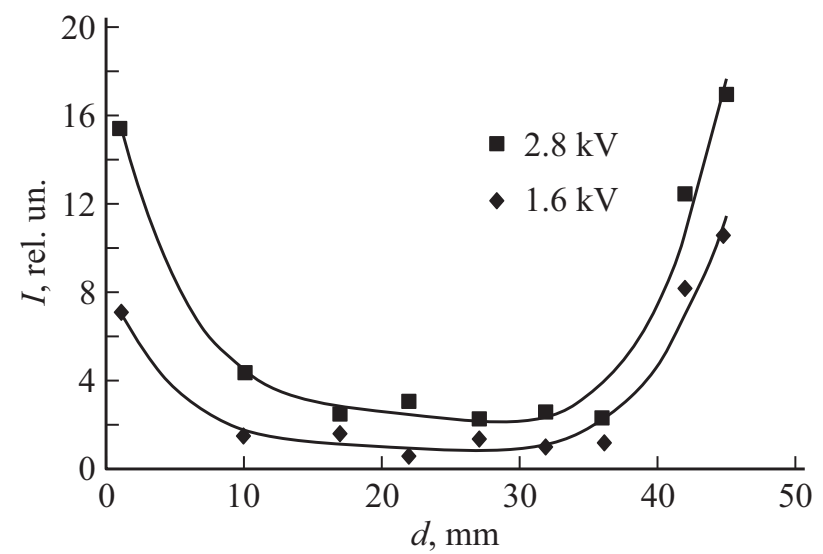

Рис. 3. Распределение интенсивности ВУФ-излучения вдоль разряда (анод слева, катод - справа).

аргумент против электронного механизма дефектообразования. Роль ионов разряда в образовании ЦО несущественна, так как глубина их проникновения в кристалл еще меньше, чем для электронов.

Далее рассмотрим возможность реализации фотонного механизма дефектообразования. В области собственного поглощения $\mathrm{LiF}$ находятся серии линий излучения азота в области 99.1-64.4 nm и кислорода в области 98.8-78.7 nm [13,14]. Электронно-дырочные пары и экситоны, образующиеся при поглощении излучения в этих линиях, формируют анионные френкелевские дефекты, являющиеся исходным продуктом для создания агрегатных ЦО. Областями газового разряда, в которых генерируется ВУФ-излучение, являются анодная светящаяся пленка и прикатодные области разряда, а не положительный столб и темное фарадеево пространство, где находились кристаллы. Это объясняется тем, что в приэлектродных областях сформирована повышенная напряженность поля $[15,16]$, за счет которой электроны способны приобретать энергию, достаточную для возбуждения более высоких энергетических уровней азота и кислорода.

Результаты прямого измерения распределения интенсивности ВУФ-излучения в разрядной трубке с помощью термолюминофора $\mathrm{CaSO}_{4} \cdot \mathrm{Mn}$ (рис. 3) подтверждают выводы о том, что основными

2 Письма в ЖТФ, 2018, том 44, вып. 15 
областями этого излучения являются приэлектродные области разряда, излучение от которых приводит к окрашиванию кристалла.

Можно заключить, что тлеющий разряд может быть успешно использован для создания тонких люминесцирующих слоев в научных и технических приложениях. По характеристикам спектров и кинетики люминесценции установлено, что в кристалле в основном образуются два типа ЦО: $F_{2}$ и $F_{3}^{+}$-центры. Показано, что основной вклад в образование ЦО в кристалле вносит фотонный механизм, а именно дефектообразование под действием ВУФ-излучения. Преимущественными источниками этого излучения являются области анодного и катодного падения напряжения тлеющего разряда. Поэтому окрашивание кристаллов вблизи этих областей наиболее эффективно.

Работа выполнена в рамках проекта № 0307-2016-0004 Программы фундаментальных научных исследований государственных академий наук на 2013-2020 гг. (II.10.1), а также проекта № 3.8401-2017/8.9 Госзадания Минобрнауки РФ на проведение научных исследований (базовая часть).

\section{Список литературы}

[1] Di Lazzaro P., Bollanti S., Flora F., Mezi L., Murra D., Torre A., Bonfigli F., Montereali R.M., Vincenti M.A. // JINST. 2016. V. 11. P. C07002.

[2] Montereali R.M., Bonfigli F., Piccinini M., Nichelatti E., Vincenti M.A. // J. Lumin. 2015. V. 170. Pt 3. P. 761-769.

[3] Barkusky F., Peth C., Mann K. // Rev. Sci. Instrum. 2005. V. 76. N 10. P. 105102.

[4] Милютина Е.В., Петровский А.Ф., Ракевич А.Л., Мартынович Е.Ф. // Письма в ЖТФ. 2014. Т. 40. В. 9. С. 64-71.

[5] Martynovich E.F., Dresvyansky V.P., Lazareva N.L., Mikhailova S.V., Konyashchenko A.V., Kostryukov P.V., Perminov B.E., Bagayev S.N. // Advanced Photonics. OSA, 2017. P. NoW2C.6.

[6] Drouin D., Couture A.R., Joly D., Tastet X., Aimez V., Gauvin R. // Scanning. 2007. V. 29. P. 92-101.

[7] Зайдель А.Н., Шрейдер Е.Я. Спектроскопия вакуумного ультрафиолета. М.: Наука, 1967. $472 \mathrm{c.}$

[8] Nakajima T. // J. Nucl. Sci. Technol. 1968. V. 5. N 7. P. 360-364.

[9] Мартынович Е.Ф. Центры окраски в лазерных кристаллах. Иркутск: ИГУ, 2004. $227 \mathrm{c}$.

[10] Лущик Ч.Б., Лущик А.Ч. Распад электронных возбуждений с образованием дефектов в твердых телах. М.: Наука, 1989. 246 с.

Письма в ЖТФ, 2018, том 44, вып. 15 
[11] Автаева С.В., Оторбаев Д.К., Скорняков А.В. // Вестн. КРСУ. 2002. Т. 2. № 2 .

[12] Voitovich A.P., Kalinov V.S., Stupak A.P., Novikov A.N., Runets L.P. // J. Lumin. 2015. V. 157. P. 28-34.

[13] Стриганов А.P., Свентищкий Н.С. Таблицы спектральных линий нейтральных и ионизованных атомов. М.: Атомиздат, 1966. $893 \mathrm{c.}$

[14] Зайдель А.Н., Прокофьев В.К., Райский С.М., Славный В.А., Шрейдер Е.Я. Таблицы спектральных линий. М.: Наука, 1977. 800 с.

[15] Лисовский В.А., Малиновский В.В., Деревянко В.А. // Вестн. Харьков. ун-та. 2013. № 1059. В. 3(59). P. 65-74.

[16] Lisovskiy V., Koval V., Kravchenko E., Yegorenkov V. // Bull. Am. Phys. Soc. 2012. V. 57. N 8. P. 78.

2* Письма в ЖТФ, 2018, том 44, вып. 15 